\title{
AGENDA EMERGENTE DE GÉNERO EN MUNICIPIOS MEXIQUENSES Y COVID-19
}

\section{EMERGENT "MEXIQUENSE" MUNICIPAL GENDER AGENDA AND COVID-19}

\author{
Gloria Jovita Guadarrama Sánchez \\ (iD) orcid.org/0000-0003-3726-5646 \\ El Colegio Mexiquense, A.C. \\ México \\ gguadarr@cmq.edu.mx
}

\begin{abstract}
The onset of the Covid-19 pandemic collapsed the world into various crises, with adverse impacts on social life, which demanded immediate action from the governments. This text presents an overview of the ways in which mexiquense municipal governments faced the health crisis, focusing on the emerging agendas aimed at addressing women issues. The analysis is supported on the exploration of the mechanisms that helped dissemination of information, available services, and posts published on digital platforms, confirming the importance of governmental communication with citizens.
\end{abstract}

Keywords: Covid-19, gender agenda, governmental communication, women.

\begin{abstract}
Resumen
La irrupción de la pandemia Covid-19 sumió al mundo en diversas crisis con impactos adversos para la vida social, que demandaron de los gobiernos agendas emergentes destinadas a atender los problemas. Este texto presenta un panorama de las formas en que los gobiernos municipales mexiquenses enfrentaron la crisis sanitaria, focalizado en la agenda emergente destinada a atender los problemas de las mujeres. El análisis se apoya en la revisión de los mecanismos que difundieron información, los servicios de apoyo y los mensajes publicados en medios digitales, confirmando la importancia de la comunicación gubernamental.
\end{abstract}

Palabras clave: Agenda de género, Covid-19, difusión gubernamental, mujeres. 


\section{Introducción}

Es un hecho que la irrupción del virus SarsCov2 (Covid-19) en la vida de los seres humanos nos arrojó a un mundo en el cual la inseguridad y la incertidumbre se acentuaron, conformando circunstancias que colocaron a las personas frente a espacios de protección y desprotección inesperados; en ellos emergieron diversas crisis en las que los patrones y certezas que tejían el orden social fueron desarticulados imponiendo de golpe nuevas formas de relación social. Asimismo, se reconoce que tales rupturas sacaron a la luz los persistentes problemas de desigualdad y exclusión prevalecientes en las sociedades. La mirada sobre el mapa y el devenir de estos procesos deja ver que esos cambios afectaron de manera distinta a los hombres y a las mujeres, con condiciones de desventaja y nuevas vulnerabilidades para ellas, como un sector de población que, previamente a la crisis sanitaria, se encontraba ya en una posición de desigualdad en sus oportunidades de acceso al bienestar.

En ese adverso panorama se nota que los problemas que enfrentan las mujeres no son solamente problemas de una cultura de discriminación histórica, sino de salud pública, pobreza y trabajo, que toman formas específicas en espacios socio-territoriales particulares configurando amenazas locales para su bienestar y que las mujeres forman conjuntos diferenciados con necesidades y demandas específicas, que requieren de estrategias también diferenciadas para su atención. Se mira, en consecuencia, que los espacios del gobierno local son los de mayor proximidad para los ciudadanos, donde se espera se generen los apoyos que permitan resolver muchos de los problemas que surgieron o se acentuaron en el contexto de la pandemia.

En las interacciones entre los problemas y las soluciones, al paso del tiempo ha sido posible notar los profundos desarreglos que han tenido lugar en las actividades económicas, laborales y en la vida cotidiana de las mujeres y, simultáneamente, las condiciones de aislamiento y la falta de apoyos cercanos para enfrentarlos. Algunos autores (Malaver-Fonseca et al., 2021) muestran que la pandemia ha afectado a las mujeres en el mundo en cinco áreas particulares: situación económica-laboral, acceso a la tecnología, salud, incremento de labores en el hogar y violencia de género. En tales circunstancias el propósito de este texto es explorar si en los espacios de los gobiernos municipales mexicanos -focalizados en los casos del Estado de México- ha sido posible ajustar o generar una agenda emergente en las políticas de género dirigida a atender los problemas de las mujeres.

La aproximación sigue el marco teórico que considera que las instituciones políticas y económicas confieren, transmiten y hacen obligatorios ciertos sentidos asociados a los fines que están en sus áreas de responsabilidad, que son internalizados e institucionalizados como valores comunes e interpretaciones compartidas de la realidad (Berger y Luckmann, 1997). Los planteamientos de Berger y Luckmann incluyen la tesis de que las instituciones conllevan los sentidos construidos como soluciones a problemas comunes, que se manifiestan en la reglamentación de las acciones sociales en áreas funcionales particulares; la comunicación de sentido adquiere importancia asociada a su control y busca integrar y legitimar las acciones dentro de esquemas de consenso social mínimos y valores compartidos (Berger y Luckmann, 1997).

En la conceptualización del papel que tienen las instituciones en la construcción de la realidad, éstas pueden ser asociadas a la integración de una agenda gubernamental de políticas públicas (Alzate-Zuluaga y Romo Morales, 2017), los problemas que son parte de la agenda pública se producen a partir de los significados compartidos por la sociedad.

En el estudio de las políticas públicas el concepto de agenda ha sido utilizado para explicar el proceso de incorporación de determinados asuntos o problemas públicos al nivel de la decisión y acción gubernamentales para su atención. Así, la agenda puede ser vista (dependiendo del enfoque teórico 
que se aplique al análisis) tanto como una etapa del proceso de elaboración de políticas o como el conjunto y tipo de estrategias que serán llevadas a cabo para atender los problemas de interés público y las demandas de los ciudadanos (Alzate-Zuluaga y Romo Morales, 2017). En la primera vertiente los estudios identifican el proceso de formación de la agenda como Agenda Setting: proceso político en el cual distintos asuntos compiten para ser atendidos a través de acciones de política pública (Dearing y Rogers, 1996). En la segunda vía el énfasis se coloca en la intervención de los actores sociales y en la construcción social de las acciones públicas, (Alzate-Zuluaga y Romo Morales, 2017).

Siguiendo esos planteamientos la construcción de una agenda emergente puede ser vista como un puente entre los sentidos, fines, capacidades y valores comunes de las políticas y dependencias formalmente constituidas para atender los problemas que afectan a las mujeres, con las demandas sociales generadas por la situación de la pandemia. El adjetivo que ubica la emergencia de los problemas y acciones que se incorporan a las políticas de género posibilita ubicarlos tanto como problemas y demandas que emergen en el entorno actual de las sociedades y/o como el conjunto de acciones urgentes que demanda una situación de crisis.

En concordancia con esta posición, Hevia y Neumeyer (2020) consideran que las intervenciones de política pública ante la crisis provocada por el virus de Covid-19, como es el caso del distanciamiento social, significaron costos e impactos negativos importantes en términos económicos y de producción para las sociedades, por lo que para lograr un retorno a los equilibrios y consensos mínimos se requiere de otras estrategias de protección basadas en la cooperación entre los actores sociales.

Sumando otra reflexión afín a estos presupuestos, Pautassi (2021) destaca la necesidad de fundar las acciones públicas que se adopten como agenda en las obligaciones correspondientes para garantizar los derechos humanos a todas las personas; obligaciones que deben ser asumidas por el Estado, los mercados, las familias y las organizaciones comunitarias, reflexión que confirma el carácter de construcción social de la agenda en torno a normas que han sido aceptadas y apropiadas por la colectividad.

Con esos elementos, se considera que, dadas las circunstancias de abandono de los espacios públicos, laborales y sociales impuestas por el confinamiento, las actividades de difusión y comunicación en las acciones públicas cobraron relevancia como medios de hacer llegar apoyos o servicios a la población, prevenir el contagio e impulsar la vacunación; al tiempo que también fueron vehículo para transferir sentidos y afirmar la visión sobre el papel y la posición que ocupan las mujeres en la sociedad. Los ejes que guían el análisis se ubican en el supuesto de que las políticas tradicionales de género implementadas por el Estado han sido rebasadas por los problemas, son poco eficientes $\mathrm{y} / \mathrm{o}$, en algunos casos, son irrelevantes frente a la dimensión de las nuevas condiciones impuestas por la pandemia. La mirada sobre estos procesos centra su atención en las características de las acciones de emprendimiento de las instancias municipales de la mujer en el Estado de México. ${ }^{1}$

El artículo abre con una reflexión sobre el confinamiento como espacio protector o como amenaza y su incidencia en la población de mujeres. Seguidamente se expone el proceso de integración de la Agenda de Género como responsabilidad municipal, para examinar, en un tercer apartado, la Agenda Municipal Emergente de Género vista a través de la difusión que realizaron los gobiernos en medios digitales -particularizados en el uso de portales de acceso a sitios informativos a través de internet- en

1 La idea central de este texto se presentó en el webinar "Tendencias actuales de la administración municipal y su impacto por la pandemia”, convocado por la UAEMéx y El Colegio Mexiquense, A.C. Una versión previa enfocada en los municipios del Estado de México con Alerta de Género fue publicada en la revista Cofactor, 10 (19), pp. 9-33. La investigación y la integración de la información contó con el apoyo de María Cervantes Oliveros, auxiliar de investigación en El Colegio Mexiquense, A.C. 
cinco rubros específicos: educación, salud, trabajo, violencia y alerta de violencia de género contra las mujeres. El estudio concluye con una reflexión que confirma que, de modo general, los gobiernos municipales mexiquenses no lograron configurar una Agenda Emergente de Género que potencialmente fuera un soporte en la atención a los problemas que enfrentan las mujeres con motivo de la pandemia, expresado en términos de abrir un camino entre las barreras para llegar a ellas.

Para abordar esos aspectos, la estrategia metodológica contempló recabar información de fuentes poco usuales en la investigación social, como son la prensa digital y las cuentas oficiales en redes sociales como Facebook y Twitter, complementándolas con páginas web institucionales. El criterio para la selección de la red social fue la frecuencia y temporalidad de uso en los portales de difusión.

Siguiendo esa línea, Facebook se seleccionó como indicador referencial, a partir de la revisión preliminar que la ubicó como la red más utilizada en las publicaciones gubernamentales y también como la de mayor accesibilidad y empleo para los usuarios de la información.

\section{El confinamiento: espacio protector o amenaza}

Como lo advierte Carrillo, aun cuando en el pasado se aplicaron medidas de aislamiento para hacer frente a las enfermedades epidémicas, el confinamiento simultáneo que desde 2020 se presentó por la Covid-19 no tiene precedente en la historia del mundo y que, si bien fue una medida que se estableció como una política sanitaria emprendida para salvar vidas, también generó efectos colaterales, algunos de ellos devastadores (Carrillo, 2021).

Para comprender mejor las repercusiones de estas medidas conviene destacar que el confinamiento en México implicó que la población lo realizara en el espacio de la casa, aunque de acuerdo con Ruiz Coronel (2021) hay un sector de la población que no tuvo esa posibilidad porque habita en el espacio público. ${ }^{2}$

En la reflexión sobre sus efectos (Torres Santana, 2020; Coneval, 2021) se ha estimado que, en el contexto particular de la pandemia en México, el confinamiento agudizó las profundas desigualdades de género por la sobrecarga en las tareas del hogar y porque trasladó el trabajo de cuidados de la economía remunerada a la no remunerada. Power (2020) señaló que incluso se incorporaron nuevas tareas al trabajo doméstico. Se observa, como lo señala Torres Santana (2020), que el trabajo de cuidados remunerado o no es siempre trabajo y es una actividad que implica costos, consume recursos y aporta valor a la sociedad; en el caso de nuestro país, está estimado en $20 \%$ del Producto Interno Bruto; buscar y elaborar los alimentos, asistir si hay enfermedad, acompañar los deberes escolares, limpiar y lavar no solamente son una sobrecarga, hacen más frágil la cotidianidad y los riesgos para el bienestar son mayores.

Adicionalmente, existen numerosos datos sobre el impacto de las clases en línea en el hogar y sobre el número de horas destinadas al trabajo doméstico que evidencian cómo se ha profundizado la brecha de género con mayores responsabilidades para las mujeres. ONU Mujeres, en conjunto con la Comisión Económica para América Latina y el Caribe, realizaron un estudio entre 18 países de la región en el que se reveló que México es el país donde se dedica más tiempo a quehaceres domésticos y cuidados no remunerados, labor que se asigna a las mujeres con $23.7 \%$, contra $7.5 \%$ de los hombres (ONU Mujeres-CEPAL, 2020).

En relación con la sobrecarga desfavorable del trabajo doméstico y el trabajo de cuidados para las mujeres durante el confinamiento, García Guzmán (2019) incluye la atención a niños en edad escolar, adultos

2 Se aplica el criterio de Baca Tavira (2002) para el uso de los términos hogar, unidad doméstica y familia para referirse a las unidades residenciales conformadas por un conjunto de personas que comparten una vivienda y un gasto. Se coincide, asimismo, con su opinión de que las redes familiares rebasan la unidad doméstica y pueden ser referidas a premisas distintas en el análisis. 
mayores y personas enfermas que no solamente demandaron mayor tiempo y esfuerzo, sino que limitaron las oportunidades de acceder al trabajo extradoméstico. ${ }^{3}$

Rea Ángeles et al. (2021) consideran que el cuidado puede definirse como la provisión diaria de atención social, física, psíquica y emocional a las personas, que se asume desde formas voluntarias hasta profesionales, remuneradas o no remuneradas. Las autoras señalan que las mujeres tienen la mayor sobrecarga de cuidados y apuntan a la existencia de lo que denominan "crisis de los cuidados" generada, entre otros factores, por la presencia de las mujeres en el ámbito laboral y social, la vida urbana, la ruptura de las redes de apoyo, la escasa participación de los hombres, la ausencia de políticas públicas y el deslinde del Estado; sustentando la necesidad de crear un sistema nacional de cuidados. Cabe notar que esa situación ya tenía un impacto negativo en la vida de las mujeres mexicanas con anterioridad a la pandemia y que el establecimiento de un Sistema Nacional de Cuidados y el derecho al cuidado digno fueron aprobados por el Congreso de la Unión en noviembre de 2020. La Ley General del Sistema Nacional de Cuidados que regula y concreta esa prescripción se encuentra en proceso.

García Guzmán (2019) y Pautassi (2020) conceptualizan el cuidado o los cuidados como derecho humano fundamental, ángulo desde el cual se identifica como obligación del Estado el ser garante de su accesibilidad y ejercicio para todos, extendiendo el concepto a "todas aquellas actividades indispensables para satisfacer las necesidades básicas de la existencia y reproducción de las personas, brindándoles elementos físicos y simbólicos que les permiten vivir en sociedad" (Pautassi, 2020: 61).

Con esos elementos se puede afirmar que las medidas de confinamiento dictadas

3 García Guzmán (2019) establece diferencias entre los conceptos "trabajo doméstico" y "trabajo de cuidados" que son relevantes para el análisis de su incidencia en la economía y el bienestar. Aquí se asume que los dos tipos de trabajo constituyen una sobrecarga para las mujeres que se incrementó durante la pandemia. en México por las autoridades responsables, vistas bajo la lupa de género tampoco han sido neutrales, ya que hay una crisis agudizada en el sistema de cuidados que usualmente recae en las mujeres de forma inequitativa y la consigna: \#QuédateEnCasa, lamentablemente, se constituyó en un factor para el incremento de los asesinatos de mujeres (ver cuadro 1). La medida, inicialmente dirigida a la población mayormente vulnerable al contagio, se hizo extensiva a la "población que realizaba actividades no esenciales", incluyendo en el confinamiento la suspensión de clases, la cancelación de actividades económicas no esenciales y eventos públicos, a partir del 30 de marzo de 2020, como una limitación relativamente voluntaria de la movilidad en el espacio público (DOF, 2020a). Estas disposiciones transformaron los hogares y domicilios en el espacio vital cotidiano, lo que generó tensiones agregadas a las de la emergencia sanitaria que, en muchos casos, derivaron en el incremento de la violencia en las relaciones familiares.

\section{Cuadro 1 \\ Asesinatos de mujeres en México (2015-2021)}

\begin{tabular}{|c|c|c|}
\hline Año & $\begin{array}{c}\text { Número de asesinatos } \\
\text { de mujeres }\end{array}$ & $\begin{array}{c}\text { Promedio } \\
\text { de mujeres } \\
\text { asesinadas al } \\
\text { día }\end{array}$ \\
\hline 2015 & $\begin{array}{c}\mathbf{2 1 4 6} \\
\text { (411 feminicidios y } 1735 \\
\text { homicidios dolosos) }\end{array}$ & 5.9 \\
\hline 2016 & $\begin{array}{c}\mathbf{2 7 9 2} \\
\text { (602 feminicidios y } 2192 \\
\text { homicidios dolosos) }\end{array}$ & 7.7 \\
\hline 2017 & $\begin{array}{c}\mathbf{3 2 7 7} \\
\text { (742 feminicidios y } 2535 \\
\text { homicidios dolosos) }\end{array}$ & 9.1 \\
\hline 2018 & $\begin{array}{c}3662 \\
\text { (885 feminicidios y } 2777 \\
\text { homicidios dolosos) }\end{array}$ & 10.1 \\
\hline 2019 & $\begin{array}{c}\mathbf{3 8 4 0} \\
\text { (972 feminicidios y } 2868 \\
\text { homicidios dolosos) }\end{array}$ & 10.5 \\
\hline 2020 & $\begin{array}{c}3770 \\
\text { (975 feminicidios y } 2795 \\
\text { homicidios dolosos) }\end{array}$ & 10.3 \\
\hline
\end{tabular}




\section{Cuadro 1 (continuación)}

\begin{tabular}{c|c|c}
\hline 2021 & 2571 & \\
$\begin{array}{c}\text { (enero- } \\
\text { agosto) }\end{array}$ & $\begin{array}{c}\text { (692 feminicidios y } 1879 \\
\text { homicidios dolosos) }\end{array}$ & $\mathbf{1 0 . 4}$ \\
\hline
\end{tabular}

Fuente: elaboración propia con datos del SESNSP (2015-2021).

Los impactos de la pandemia y del confinamiento en distintos aspectos de la economía, el trabajo, el bienestar y la calidad de vida de las personas en México han sido objeto de diversos estudios (Coneval, 2021; Ziccardi, 2020; Montes de Oca Zavala et al., 2021); aquí interesa destacar algunos puntos de incidencia diferenciada entre los hombres y las mujeres, como es el caso de la violencia en razón de género; en coincidencia con planteamientos que advierten que las condiciones de desigualdad recrudecieron sus efectos en diferentes poblaciones (Montes de Oca Zavala et al., 2021).

En el mismo sentido, debido a la posición desigual que ya ocupaban en las estructuras del mercado laboral, la pandemia ha representado un golpe económico para las mujeres en México. En el reporte de la Encuesta Nacional de Ocupación y Empleo correspondiente a julio de 2020, la población económicamente activa fue de 52.6 millones de personas, con una tasa de participación de $39.2 \%$ en las mujeres en edad de trabajar $(20,619,200)$ y de $72.2 \%$ en los hombres $(37,977,200)$. Es decir, hubo una reducción del $45 \%$ al $39 \%$ en la participación de mujeres (Inegi, 2020).

Las mujeres también han visto reducidas sus oportunidades de acceso a la salud. El confinamiento, la escasa disponibilidad de servicios médicos y de medicamentos en los espacios hospitalarios ocasionaron una disminución en la atención ginecológica; la provisión de anticonceptivos y las consultas tuvieron una reducción considerable, hubo muchas mujeres embarazadas contagiadas, por no hablar de las enfermeras en primera línea y sin la protección adecuada. ONU Mujeres-CEPAL (2020) estiman que las mujeres constituyen $72.8 \%$ de personas ocupadas en los sistemas de salud de América Latina, para quienes las condiciones de tra- bajo -que ya eran precarias- se han vuelto extremas con el incremento de horas laborales y los riesgos de contagio por Covid-19. Asimismo, la organización advierte que "en este nuevo escenario, cuando los sistemas sanitarios están operando al máximo de sus capacidades, mucha de la atención de salud se traslada a los hogares, lo que, sin políticas de corresponsabilidad, aumenta la presión ejercida sobre el tiempo de cuidados, en particular en el caso de las mujeres". Con esos datos consideran que la pandemia tendrá entre sus efectos un retroceso de 10 años en los avances logrados en equidad para las mujeres (CEPAL, 2021: 2).

En México los registros apuntan a problemas similares. El Instituto Nacional de las Mujeres (Inmujeres) marca una dimensión diferencial en los impactos que la Covid-19 ha tenido en lo que concierne a la salud; señala que de las 472,781 personas que se desempeñan en labores de enfermería, $79.1 \%$ son mujeres y $20.9 \%$ son hombres y que el trabajo de cuidados remunerado también descansa en las mujeres, confirmando que "la división sexual del trabajo coloca a las mujeres enfermeras y cuidadoras en un mayor riesgo de exposición al contagio comparadas con los hombres" (Inmujeres, 2020: 4).

En resumen, es posible afirmar que los hogares han sufrido una transformación radical en sus funciones durante el confinamiento y que los efectos negativos de la pandemia se distribuyen de manera desigual siguiendo las acendradas líneas de vulnerabilidad que marcan a las mujeres. Asimismo, el confinamiento pensado como un ámbito de protección, modificó la vida de los hogares conformando nuevos riesgos y problemas en las condiciones de vida de las mujeres.

La premisa que sustenta este texto establece que tales efectos constituyen problemas graves y urgentes que demandan reestructurar e innovar las políticas de atención a las mujeres; acciones que se articulan en el ámbito local y comunitario, por lo que es necesario revisar la Agenda Municipal de Género. 


\section{La Agenda Emergente de Género como responsabilidad municipal}

A partir de aceptar que México continúa siendo un país en el que las brechas de género continúan siendo muy amplias y que actualmente se vive como un territorio hostil para la convivencia en el que los indicadores de violencia en general y de violencia de género en particular son muy elevados, se puede observar que las políticas públicas de atención a las mujeres no han sido claras y consistentes en sus objetivos, estrategias y metas, con cambios en la posición del gobierno que se han traducido en restricciones importantes en los recursos y mecanismos para enfrentar los problemas que las afectan. ${ }^{4}$

Podemos decir también que en un periodo de 20 o 30 años, las funciones y el papel que tenían los gobiernos municipales para enfrentar los problemas públicos se han ampliado a causa no solamente de los procesos de descentralización de competencias y del establecimiento de nuevas formas de operación de las políticas, sino con los cambios registrados en la composición de la población, las nuevas necesidades del bienestar y las demandas ciudadanas. Como parte de esos procesos las políticas de género fueron asumidas como ámbitos de competencia municipal y, a partir de 2000, se fueron incorporando a la organización político-administrativa de los gobiernos locales con áreas y estructuras específicas. Esto significó que los Ayuntamientos reconocieran responsabilidades en su instrumentación y, es a partir de ello que entre sus atribuciones está el desarrollo de una Agenda Municipal de Género.

Cabe notar que la intervención municipal se configura como una obligación sustentada en los artículos 23, 24, 25, 26, 27 y

\footnotetext{
4 Las oscilaciones en la posición del gobierno se advierten cuando, en tanto que Inmujeres, conjuntamente con la iniciativa Spotlight, difunden el video \#NoEstásSola, enfocado a la prevención de la violencia contra las mujeres en el hogar en tiempos de Covid-19, instando a llamar al número telefónico de emergencias 911, el Presidente de la República Andrés Manuel López Obrador declara que las Ilamadas de emergencia por violencia contra género durante la pandemia son falsas (Inmujeres, 2020; Kitroeff, 2020).
}

28 de la Ley General para la Igualdad entre Mujeres y Hombres que mandatan a los gobiernos instrumentar la política en materia de igualdad, así como diseñar, implementar y evaluar estrategias municipales. Esas prescripciones dan sustento legal a la participación municipal en el Sistema Nacional para la Igualdad entre Mujeres y Hombres, el cual se define como el conjunto orgánico y articulado de estructuras, relaciones funcionales, métodos y procedimientos que establecen las dependencias con las organizaciones de los diversos grupos sociales y con las autoridades de los estados, la Ciudad de México y los municipios, a fin de encauzar la Política Nacional en Materia de Igualdad entre Mujeres y Hombres. ${ }^{5}$

Desde una perspectiva institucional, como la denomina Alejandra Ríos Cázares (2014), los factores clave o Mecanismos para el Adelanto de las Mujeres (MAM) determinan la capacidad institucional y la viabilidad de las estrategias diseñadas para el logro de los objetivos. Entre ellos están que las instituciones responsables ocupen una ubicación central y estratégica en la estructura gubernamental y cuenten con recursos materiales e institucionales suficientes para hacer efectivo su mandato. Estas premisas son el sustento para señalar que, en el caso de las instancias municipales de las mujeres, son presupuestos que no se han podido establecer y consolidar.

Para el caso del Estado de México, una mirada detallada revela que aun cuando formalmente los 125 municipios mexiquenses cuentan actualmente con una instancia municipal responsable, la situación y condición de su estructura organizacional, su posición en la jerarquía gubernamental, los recursos y apoyos con los que cuentan son muy diversos. ${ }^{6}$ Por ejemplo, Toluca cuenta con un

5 La visión que sustenta la figura de los sistemas nacionales en la administración pública mexicana es la de su integración como mecanismo sustantivo de coordinación de las estrategias de la política pública porque vincula las acciones de los distintos niveles de gobierno en torno a las responsabilidades y atribuciones para el logro de objetivos nacionales.

6 Las formas de constitución son diversas: 98 son identificados como Institutos Municipales de la Mujer, 12 como Consejos Municipales de la Mujer, 6 como 
instituto autónomo para ello, y en cambio otros municipios como Texcoco sólo cuentan con una coordinación dependiente de la Dirección de Desarrollo Social, Educativo y Deporte. El conjunto heterogéneo de las dependencias confirma la premisa de que la Agenda Municipal es construida de manera diferenciada adaptándose a las condiciones de cada territorio. Un punto clave para entender cómo y por qué operan las dependencias de forma tan diversa radica en reconocer que su posición en la estructura municipal determina su acceso a los recursos humanos y materiales, la estabilidad de sus programas, sus posibilidades de obtener la cooperación y el apoyo de otros actores, e incluso su subsistencia.

Como parte del mismo panorama de escasa fortaleza institucional se ubican las limitaciones de las dependencias para integrar un conjunto de activos y capacidades que apoyen su funcionamiento. Resultados de investigación sobre las capacidades de los organismos mexiquenses de la mujer en 2009 (Guadarrama, 2021) los colocaban en una línea de capacidades estructurales que combinan recursos financieros, materiales y humanos, identificando que la proporción de dependencias que no alcanzan capacidades medianas o aceptables es mayoritaria, pues solamente 13 municipios (10.4\%) se estimaron con capacidades suficientes para cumplir sus funciones.

Es en ese marco que las dependencias municipales que atienden a las mexiquenses con políticas públicas, usualmente identificadas como políticas de género, debieron hacer frente a un alud de problemas asociados a la Covid-19 mediante un conjunto de acciones que aquí se ha denominado La Agenda Emergente Municipal de Género, la cual resume las posibilidades que se tuvieron para hacer ajustes y diseñar nuevas estrategias. La

Direcciones de Atención a la Mujer, 1 Secretaría de la Mujer (la Secretaría de las Mujeres Naucalpenses y la Igualdad Sustantiva), 6 Coordinaciones de Atención a la Mujer, 1 Subdirección de Atención a la Mujer y 1 Unidad para la Protección de los Derechos de las Mujeres. Cabe destacar que el establecimiento del Instituto Municipal de la Mujer de Toluca como organismo público descentralizado se realizó mediante decreto de la LX Legislatura local el 8 de agosto de 2019.
Agenda Emergente Municipal de Género representa el conjunto de responsabilidades, compromisos y estrategias que asumen los gobiernos para dar respuesta a los problemas sociales de las mujeres y se integra por los mecanismos e instrumentos para desarrollar su actividad, buscar el bienestar y garantizar los derechos de las personas.

\section{"La Agenda Emergente Municipal de Género". Una mirada a través de los mecanismos de difusión}

En un apartado anterior se puntualizó que las medidas para enfrentar la emergencia sanitaria y los propios efectos negativos de la pandemia tuvieron impactos en los distintos espacios y estructuras que articulan el orden en las sociedades: en las instituciones del estado, en las actividades económicas y el empleo, en las familias y en las organizaciones sociales.

En el caso de los gobiernos municipales, la administración se vio obligada a suspender muchas de sus actividades y en algunos casos hubo de cerrar sus puertas a demandas, trámites y servicios para los ciudadanos; en tales circunstancias adquirieron preponderancia las acciones de comunicación a través de las páginas digitales de los gobiernos, por lo que para responder a la pregunta sobre si los gobiernos municipales mexiquenses como las instancias de mayor proximidad con las mujeres durante la pandemia habían podido ajustar o innovar sus políticas públicas, a modo de configurar una agenda emergente, se examinaron principalmente los medios digitales de difusión de los gobiernos municipales.

La mirada sobre los medios de difusión adquiere relevancia si se considera que la información que proporcionan a los ciudadanos ayuda a la concientización sobre los problemas públicos y puede generar interacciones que favorecen su participación y colaboración en su atención. Otro punto de relevancia estriba en el reconocimiento de que las acciones comunicativas a través de medios digitales y redes sociales pueden ser un auxilio durante las crisis relativas a la sa- 
lud pública, cuestiones sociales, transporte y desastres naturales (Graham et al., 2015).

Asimismo se tomó en cuenta que la difusión de las acciones por las dependencias concentra líneas sustantivas del discurso gubernamental sobre los problemas públicos, las cuales no necesariamente tienen el soporte de las herramientas y recursos para enfrentar los problemas, por lo que los reportes que se concentran en el análisis podrían ser diferentes en un sentido positivo o negativo de lo que realmente realizan las dependencias; esto significa que pueden contar con un mayor o menor margen de acción de las que difunden, o bien, que las que difunden no reflejen estrictamente lo que están en posibilidades de ofrecer como apoyos para las mujeres, pero resulta evidente que son mensajes que contribuyen a la conformación de una agenda política.

En la misma línea de reflexión que estructura el análisis es necesario notar sus limitaciones en las circunstancias particulares de la pandemia que no permitieron estimar o concluir sobre las capacidades generales de atención de los organismos que atienden a los problemas de las mujeres, pero vierten datos que sí permiten visibilizar la presencia o ausencia de una agenda emergente, sus ajustes y sus limitaciones. En ese contexto, un punto que afianzó la decisión de utilizar los medios de difusión digital para el análisis fue la reducción que tuvo el uso de otros medios por las dependencias municipales, impuesta tanto por la limitación de acceso a los espacios públicos como por sus elevados costos.

Se advierte igualmente que no se pretende trazar un perfil de la comunicación general que desarrollan los gobiernos municipales, ya que no se incluye la difusión en medios como la prensa escrita, la radio, los paneles, conferencias o espectaculares; se priorizan, en cambio, las redes y sitios web por su accesibilidad desde los teléfonos móviles, IPad o computadora.

Con esa intencionalidad se revisaron los sitios web oficiales y redes sociales de los 125 gobiernos municipales del Estado de México; en estos espacios se identificó la información sobre actividades, servicios y programas que atendieran problemas y circunstancias específicamente relacionadas con las mujeres durante el confinamiento por Covid-19.

De no hallarse publicaciones o ligas de interés que refirieran a contenidos e información sobre estos problemas, la búsqueda se derivaba al directorio de organismos y direcciones del gobierno municipal para identificar directamente la Instancia de atención a las mujeres como la dependencia responsable en el municipio; una vez identificada la instancia, si contaba con página web, ésta fue utilizada como referente principal para explorar el contenido que se compartió a partir de febrero de 2020 y hasta julio de 2021. ${ }^{7}$

Los campos de atención, apoyos o servicios identificados de acuerdo con la intención general de la información fueron considerados como el contenido de la Agenda Municipal Emergente de Género: 1) educación, 2) salud, 3) trabajo y 4) violencia. Adicionalmente se consideró el campo de difusión de actividades en municipios con alerta de género.

La difusión realizada por los gobiernos municipales se clasificó en los niveles alto, medio o nulo de acuerdo con el registro de actividad en páginas web y redes sociales; en donde los niveles: 1) alto, refieren a la publicación continua, diaria y/o semanal durante todo el período del confinamiento; 2) medio, a publicaciones mensuales, pausadas e interrumpidas, sin seguimiento; y 3) nulo, cuando no se identificó ninguna publicación, en muchos casos, no se contaba con página de difusión de actividades.

\footnotetext{
7 De los 125 municipios, en el momento en el que se realizó la investigación, 9 no cuentan página web del ayuntamiento, estos son: Coatepec Harinas (sitio caído), Cocotitlán (sitio web no disponible), Otzoloapan (sitio web no disponible), Papalotla (sitio web no disponible), Temascalcingo (sitio web fuera de servicio), Temascaltepec (sitio web fuera de servicio), Tepetlaoxtoc (sitio web fuera de servicio), Tequixquiac (sitio web no disponible) y Villa del Carbón (sitio web no disponible). En el documento se contemplan estos municipios comprendidos en el índice de difusión nulo.
} 


\section{La agenda emergente educativa}

Se identificaron contenidos y publicaciones de seguimiento a la situación escolar de niños y niñas; fomento a la educación desde casa, apoyo ante las dificultades generadas por el confinamiento; actividades, servicios o acciones que facilitaran información y medios para evitar la deserción escolar; conferencias, talleres o asesorías que involucraran a niñas y niños. Información y atención a los problemas de acceso y cuidado que los programas educativos desde casa implicaban principalmente para las madres. De los 119 municipios con página web, 19 mantuvieron un alto índice de difusión y seguimiento a la educación; y 5 un índice medio (ver cuadro 2 ). ${ }^{8}$

\section{Cuadro 2 \\ Niveles de difusión en el rubro de educación en las páginas web y redes sociales de los municipios mexiquenses (2020-2021)}

\begin{tabular}{|c|c|}
\hline Índice & Municipios \\
\hline Alto & 19 \\
\hline Medio & 5 \\
\hline Nulo & 101 \\
\hline
\end{tabular}

Fuente: elaboración propia con base en datos de las páginas web de ayuntamientos y redes sociales de los organismos municipales de la mujer.

\section{La agenda emergente de apoyo a la salud}

Se identificaron contenidos y publicaciones referidas a la salud de las mujeres du-

8 Los municipios con un alto índice de actividad en plataformas digitales en el rubro de educación durante el confinamiento son: Almoloya del Río, Atenco, Axapusco, Coyotepec, Chimalhuacán, Huehuetoca, Jaltenco, Otzolotepec, Rayón, San Felipe del Progreso, San Mateo Atenco, Tenancingo, Tenango del Valle, Teotihuacán, Tepetlixpa, Texcalyacac, Tianguistenco, Toluca y Tultitán. Los municipios con un índice medio de actividad en plataformas digitales en el rubro de educación durante el confinamiento son: Chalco, Donato Guerra, Ixtapaluca, Tultepec y Valle de Chalco Solidaridad. El resto de los municipios tiene un índice nulo de difusión en páginas web. rante el contexto del confinamiento; no se registró lo que específicamente hablaba de Covid-19 para abrir el espacio a identificar otras áreas y servicio de salud que fueran atendidas. Los asuntos de salud en referencia a la población femenina que se ubicaron principalmente son: cáncer de mama, educación sexual y reproductiva, salud mental, prevención de adicciones y campañas de salud preventiva. De los 125 municipios, 16 manifestaron un alto índice de actividad de difusión y seguimiento a cuestiones de salud de las mujeres y 7 un índice medio (ver cuadro 3). ${ }^{9}$

\section{Cuadro 3 \\ Niveles de difusión en el rubro de salud en las páginas web y redes sociales de los municipios mexiquenses (2020-2021)}

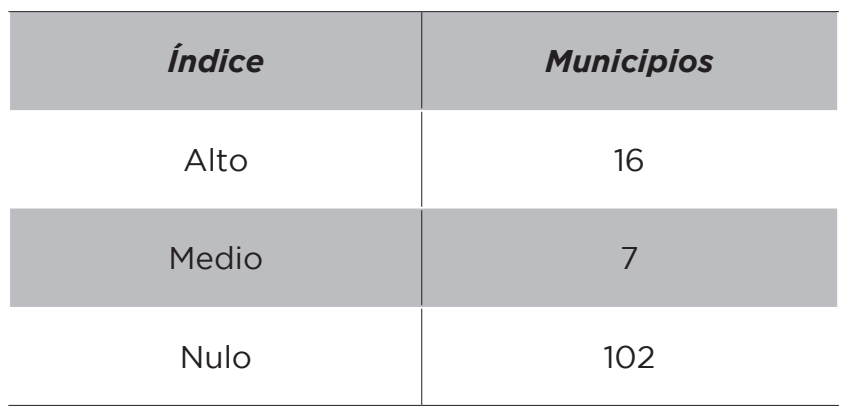

Fuente: elaboración propia con base en datos de las páginas web de ayuntamientos y redes sociales de los organismos municipales de la mujer.

\section{La agenda emergente de apoyo al trabajo}

Se exploró la difusión y atención a los siguientes problemas: desempleo e incremento del trabajo doméstico no remunerado de mujeres, así como el trabajo de maestras, enfermeras y trabajadoras del hogar. La selección de los problemas se sustentó

9 Los municipios con un alto índice de actividad en plataformas digitales en el rubro de salud durante el confinamiento son: Almoloya del Río, Atenco, Axapusco, Coacalco, Coyotepec, Chimalhuacán, Huehuetoca, Jaltenco, Otzolotepec, Rayón, Tenango del Valle, Teotihuacán, Texcalyacac, Tianguistenco, Toluca y Tultitlán. Los municipios con un índice medio de actividad en plataformas digitales en el rubro de salud durante el confinamiento son: Donato Guerra, Ixtapaluca, Malinalco, San Felipe del Progreso, San Mateo Atenco, Tepetlixpa y Valle de Chalco Solidaridad. El resto de los municipios tiene un índice nulo de difusión en páginas web. 
en fuentes documentales que los reportan como los de mayor impacto negativo para las mujeres durante la pandemia (García Guzmán, 2019; Inmujeres, 2020; Olivera y Olivera, 2021). De los 125 municipios, 12 reportaron un alto grado de actividad de tipo apoyo, atención y seguimiento y 3 un índice medio (ver cuadro 4)..$^{10}$

\section{Cuadro 4}

Niveles de difusión en el rubro de trabajo en las páginas web y redes sociales de los municipios mexiquenses (2020-2021)

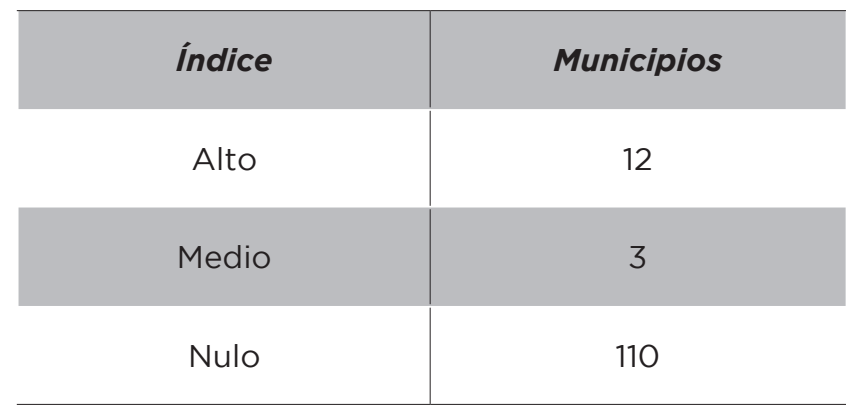

Fuente: elaboración propia con base en datos de las páginas web de ayuntamientos y redes sociales de los organismos municipales de la mujer.

\section{La agenda emergente contra la violencia de género}

Se exploró la difusión de información que tuviera que ver con la atención y prevención de la violencia contra las mujeres. Este rubro ha sido el que más atención ha recibido por parte de las unidades municipales, se consideró que la atención, asesoría y el seguimiento de las actividades, servicios y programas para combatir y denunciar hechos de violencia no se detuviera a pesar de las condiciones por el confinamiento. De los 125 municipios mexiquenses, 26 registraron un alto nivel de actividad en el seguimiento, difusión y divulgación, tanto de información

10 Los municipios con un alto índice de actividad en plataformas digitales en el rubro de trabajo durante el confinamiento son: Almoloya del Río, Atenco, Axapusco, Coacalco, Jaltenco, San Mateo Atenco, Tenancingo, Tenango del Valle, Tianguistenco, Toluca, Tultepec y Tultitán. Los municipios con un índice medio de actividad en plataformas digitales en el rubro de trabajo durante el confinamiento son: Almoloya de Juárez, Chalco y Tepetlaoxtoc. El resto de los municipios tiene un índice nulo de difusión en páginas web. relevante para prevenir, denunciar y saber actuar ante hechos de violencia, como de mecanismos municipales y estatales para conseguir asesoría o asistencia psicológica y jurídica vía telefónica o por plataformas digitales como apps, botones de pánico o chats administrados por el gobierno municipal de la entidad. Únicamente 6 municipios mostraron un nivel medio de difusión, atención y seguimiento en lo antes descrito (ver cuadro 5)."

\section{Cuadro 5}

Niveles de difusión en el rubro de violencia en las páginas web y redes sociales de los municipios mexiquenses (2020-2021)

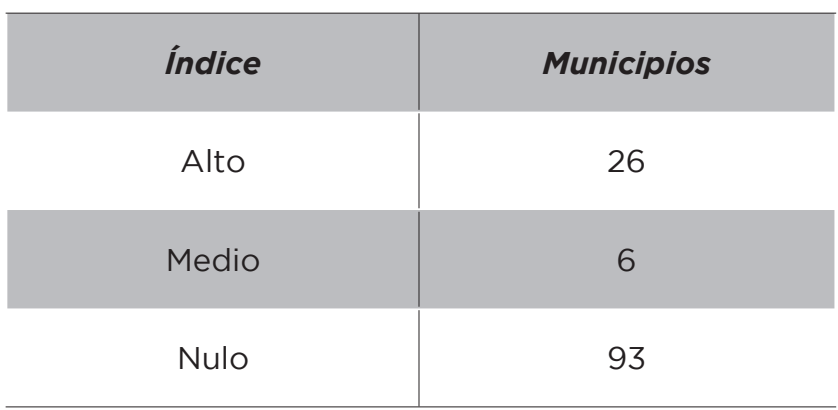

Fuente: elaboración propia con base en datos de las páginas web de ayuntamientos y redes sociales de los organismos municipales de la mujer.

En resumen, la exploración muestra la ausencia o precariedad de la difusión de una agenda emergente de género (ver gráfica 1).

11 Los municipios con un alto índice de actividad en plataformas digitales en el rubro de violencia durante el confinamiento son: Almoloya del Río, Atenco, Axapusco, Coacalco, Coyotepec, Chalco, Chimalhuacán, Donato Guerra, Ecatepec, Huehuetoca, Ixtapaluca, Jaltenco, Otzolotepec, Rayón, San Felipe del Progreso, San Mateo Atenco, Tenancingo, Tenango del Valle, Teotihuacán, Tepetlaoxtoc, Tepetlixpa, Texcalyacac, Tianguistenco, Toluca, Tultepec y Tultitlán. Los municipios con un índice medio de actividad en plataformas digitales en el rubro de violencia durante el confinamiento son: Acolman, Almoloya de Juárez, Atlautla, Malinalco, Cuautitlán Izcalli y Valle de Chalco Solidaridad. El resto de los municipios tiene un índice nulo de difusión en páginas web. 


\section{Gráfica 1}

Nivel de difusión general en los cuatro rubros en páginas web y redes sociales de los municipios mexiquenses (2020-2021)

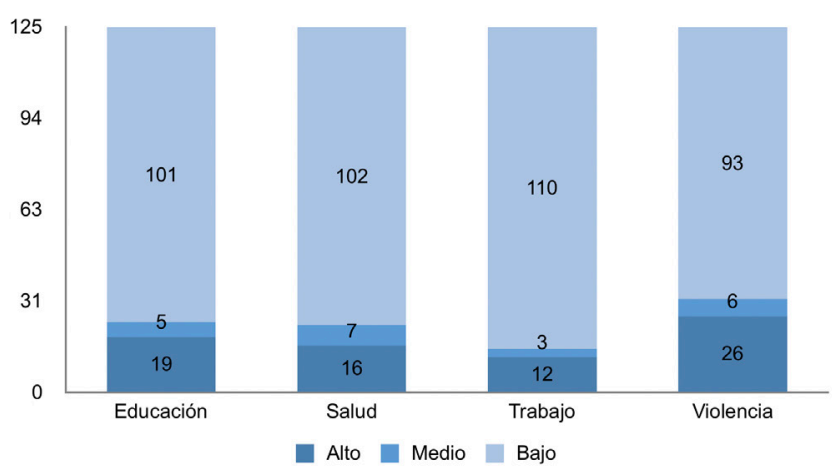

Fuente: elaboración propia con base en datos de las páginas web de ayuntamientos y redes sociales de los organismos municipales de la mujer.

\section{La agenda municipal emergente en el contexto de la alerta de género}

En el contexto de la pandemia, uno de los mayores problemas ha sido el incremento de la violencia contra las mujeres, problema que ya había sido identificado previamente como una emergencia de salud pública en el país y en el territorio mexiquense, por lo cual se emitió en 2015 una declaratoria de Alerta de Violencia de Género Contra las Mujeres AVGM.12 La AVGM es un mecanismo de coordinación intergubernamental entre la Federación, las entidades federativas y los municipios previsto en la Ley General de Acceso de las Mujeres a una vida Libre de Violencia; el conjunto de acciones se orienta

12 Datos del Secretariado Ejecutivo del Sistema Nacional de Seguridad Pública (SESNSP) de enero a julio de 2019 confirman que 2173 mujeres fueron asesinadas intencionalmente en el país, 1610 de esas muertes se registraron como homicidio doloso y 563 como feminicidios; lo que significa un promedio de 10.2 mujeres que diariamente pierden la vida a causa de la violencia (SESNSP, 2019). A ello se suma el incremento en la violencia doméstica registrado durante el periodo de confinamiento que impuso la pandemia por la Covid-19, ya que solamente en marzo de 2020, cuando comenzó el confinamiento, se recibieron 115,614 Ilamadas telefónicas de emergencia por incidentes vinculados a violencia contra las mujeres -incremento notable en relación a las 76,824 registradas en el mismo mes en 2019-, cifras que incluyen: Incidentes de Violencia contra la Mujer, Incidentes de Abuso Sexual, Incidentes de Hostigamiento Sexual, Incidentes de Violación, Incidentes de Violencia en Pareja e Incidentes de Violencia Familiar (SESNSP, 2020) a prevenir, sancionar y erradicar la violencia en un territorio determinado; la AVGM debe declararse cuando hay un incremento de casos de feminicidio. Para el caso del Estado de México el decreto del Poder Ejecutivo estatal se emitió a solicitud de organizaciones de la sociedad civil y contempló 11 municipios: Chalco, Chimalhuacán, Cuautitlán IzcaIli, Ecatepec de Morelos, Ixtapaluca, Naucalpan de Juárez, Nezahualcóyotl, Tlalnepantla de Baz, Toluca, Tultitlán y Valle de Chalco Solidaridad (Gaceta del Gobierno, 2015).

Transcurridos seis años de ese pronunciamiento se observa que la estrategia no ha incidido en la disminución de los hechos de violencia y, en 2019, se estimó necesario emitir una segunda alerta enfocada a la desaparición de niñas, adolescentes y mujeres en siete de los municipios que ya estaban considerados en la primera declaración y gradualmente se fueron asignando recursos para su aplicación en los rubros de prevención, seguridad y justicia (ver cuadro 6); no obstante lo anterior, la ejecución de estas estrategias no parece lograr la consistencia que permita atender con suficiencia los problemas y, en este año el reporte del Secretariado Ejecutivo del Sistema Nacional de Seguridad Pública (SESNSP, 2021) consignó 40 feminicidios ocurridos entre enero y agosto de 2021, en los 11 municipios considerados en este mecanismo de atención emergente (ver gráfica 2).

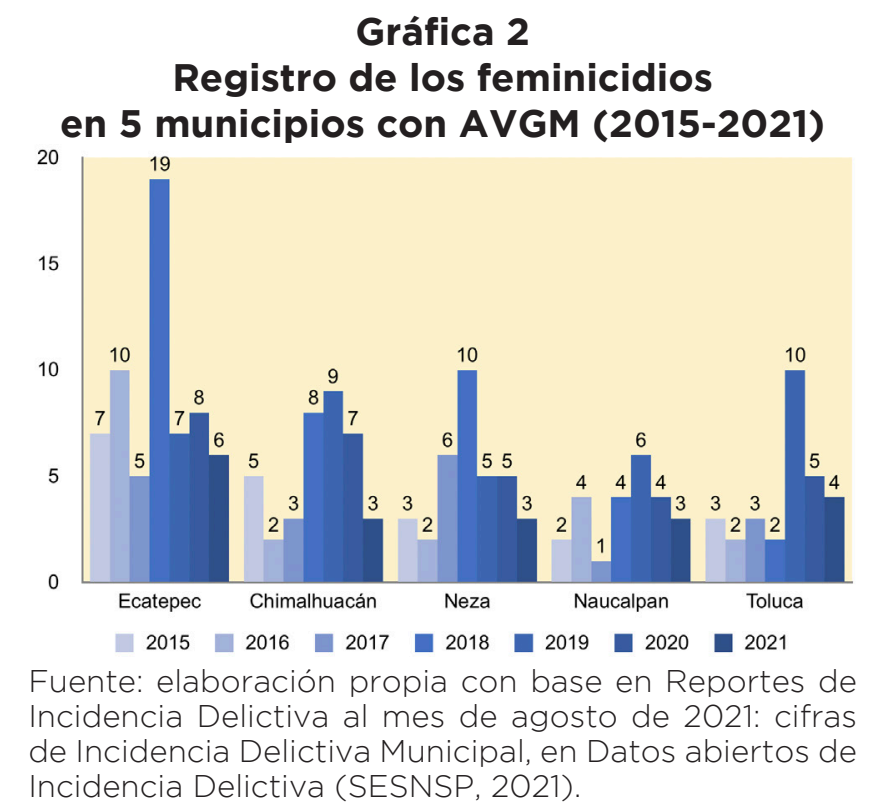

\section{en 5 municipios con AVGM (2015-2021)}

20

Incidencia Delictiva al mes de agosto de 2021: cifras de Incidencia Delictiva Municipal, en Datos abiertos de Incidencia Delictiva (SESNSP, 2021). 


\section{Cuadro 6 \\ Recursos para la Mitigación de las Alertas de Violencia de Género por Feminicidio y Desaparición (2020 y 2021)}

\begin{tabular}{|c|c|c|c|c|c|}
\hline $\begin{array}{c}\text { Municipios con } \\
\text { Declaratoria de Alerta } \\
\text { de Violencia de } \\
\text { Género }\end{array}$ & $\begin{array}{c}\text { Municipios con } \\
\text { Declaratoria de } \\
\text { Alerta de Violencia } \\
\text { de Género contra } \\
\text { las Mujeres por } \\
\text { Desaparición de } \\
\text { Niñas, Adolescentes y } \\
\text { Mujeres }\end{array}$ & $\begin{array}{c}\text { AVG por } \\
\text { feminicidio } \\
\text { 2020: } \\
100 \text { millones de } \\
\text { pesos } \\
\text { (presupuesto } \\
\text { ejercido) }\end{array}$ & $\begin{array}{c}\text { AVG por } \\
\text { desaparición } \\
\text { 2020: } \\
20 \text { millones de } \\
\text { pesos } \\
\text { (presupuesto } \\
\text { ejercido) }\end{array}$ & $\begin{array}{c}\text { AVG por } \\
\text { feminicidio } \\
\text { 2021: } \\
\\
80 \text { millones de } \\
\text { pesos } \\
\text { (presupuesto } \\
\text { por ejercer) }{ }^{*}\end{array}$ & $\begin{array}{c}\text { AVG por } \\
\text { desaparición } \\
\text { 2021: } \\
20 \text { millones } \\
\text { de pesos } \\
\text { (presupuesto } \\
\text { por ejercer) * }\end{array}$ \\
\hline Chalco & - & $\$ 9,637,670$ & - & $11.1 \mathrm{mdp}$ & - \\
\hline Chimalhuacán & Chimalhuacán & $\$ 5,192,634$ & $\$ 2,227,477$ & $6.2 \mathrm{mdp}$ & $2.4 \mathrm{mdp}$ \\
\hline Cuautitlán Izcalli & Cuautitlán Izcalli & $\$ 7,515,216$ & $\$ 1,835,272$ & $7.5 \mathrm{mdp}$ & $2.1 \mathrm{mdp}$ \\
\hline Ecatepec de Morelos & Ecatepec de Morelos & $\$ 5,152,132$ & $\$ 1,577,194$ & $7.5 \mathrm{mdp}$ & $2 \mathrm{mdp}$ \\
\hline Ixtapaluca & Ixtapaluca & $\$ 6,172,499$ & $\$ 1,869,644$ & $4.7 \mathrm{mdp}$ & $3.3 \mathrm{mdp}$ \\
\hline Naucalpan de Juárez & - & $\$ 7,591,835$ & - & $7.1 \mathrm{mdp}$ & \\
\hline Nezahualcóyotl & Nezahualcóyotl & $\$ 8,645,837$ & $\$ 2,404,910$ & $7.2 \mathrm{mdp}$ & $2 \mathrm{mdp}$ \\
\hline Tlalnepantla de Baz & - & $\$ 9,171,343$ & - & $5.1 \mathrm{mdp}$ & - \\
\hline Toluca & Toluca & $\$ 9,734,923$ & $\$ 1,911,624$ & $9.4 \mathrm{mdp}$ & $3.2 \mathrm{mdp}$ \\
\hline Tultitlán & - & $\$ 5,520,325$ & & $7.9 \mathrm{mdp}$ & \\
\hline $\begin{array}{l}\text { Valle de Chalco } \\
\text { Solidaridad }\end{array}$ & $\begin{array}{l}\text { Valle de Chalco } \\
\text { Solidaridad }\end{array}$ & $\$ 5,665,587$ & $\$ 3,145,875$ & $5.9 \mathrm{mdp}$ & $4.6 \mathrm{mdp}$ \\
\hline
\end{tabular}

Fuente: elaboración propia con información de la CONAVIM (2020) y Poder Legislativo del Estado de México (2021).

Nota: en la asignación de recursos, la autoridad estatal toma en cuenta para el rubro de los feminicidios: el índice delictivo, el número de atenciones brindadas por la Comisión Ejecutiva y la asignación ejercida el año anterior, así como los subejercicios y su participación en el programa Spotligth. Referente a desapariciones considera la población de mujeres en el municipio y el número de mujeres por localizar en el año anterior. *Al momento de la investigación, los datos sobre el presupuesto de 2020 refieren al informe de la CONAVIM (2020) con núm. de oficio 222BO21AO/539/202O, en el que se desglosa la cantidad en pesos del presupuesto ejercido; por otro lado, la información sobre el presupuesto correspondiente al 2021 que aparece expresado en mdp proviene del comunicado publicado por el Poder Legislativo del Estado de México (2021) en el que no se desglosa el presupuesto porque éste ha sido, a la fecha, sólo asignado, no ejercido.
En ese contexto resulta evidente que la irrupción de la pandemia detonó el imperativo de construir una agenda para enfrentar no solamente el incremento del feminicidio, sino el de los delitos de secuestro, acoso, hostigamiento y violación (SESNSP, 2021); agenda que pudo ser observada y resumida en los siguientes niveles de su difusión a través de medios digitales (ver cuadros 7 y 8 ). 


\section{Cuadro 7 \\ Niveles de difusión en el ámbito de mitigación de la violencia de género en las páginas web y redes sociales de los municipios con AVGM (2020-2021)}

\begin{tabular}{|c|c|c|}
\hline Instancia municipal & Principales acciones & $\begin{array}{l}\text { Nivel de } \\
\text { difusión }\end{array}$ \\
\hline $\begin{array}{l}\text { Instituto Municipal de las Mujeres e } \\
\text { Igualdad de Género de Ecatepec. } \\
\text { Facebook: IMMIGEcatepec }\end{array}$ & 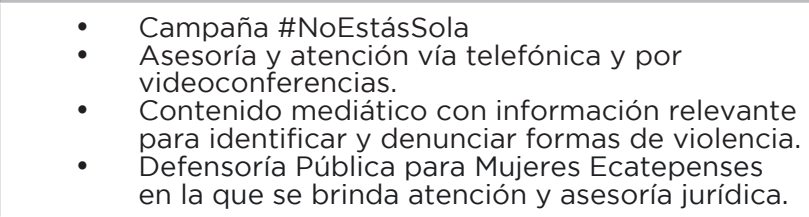 & Alto \\
\hline Instituto de la Mujer Nezahualcóyotl & $\begin{array}{l}\text { - } \quad \text { El sitio de Facebook cesó actividades en } 2015 . \\
\text { ua página web del ayuntamiento sólo contiene } \\
\text { un resumen de las actividades realizadas por el } \\
\text { Instituto, una dirección y número telefónico. }\end{array}$ & Nulo \\
\hline $\begin{array}{l}\text { Instituto Municipal de la Mujer de } \\
\text { Chimalhuacán. } \\
\text { Facebook: } \\
\text { InstitutoMunicipaldelaMujerChimalhuacan. } \\
\text { Página web del ayuntamiento: Consejo } \\
\text { municipal de la mujer. }\end{array}$ & $\begin{array}{l}\text { - En la página web del ayuntamiento se publican } \\
\text { constantemente las acciones realizadas por el } \\
\text { Instituto para combatir la violencia de género. } \\
\text { En el portal de Facebook se difunde contenido } \\
\text { mediático con números de emergencia e } \\
\text { información relevante para identificar y } \\
\text { denunciar formas de violencia. }\end{array}$ & Alto \\
\hline $\begin{array}{l}\text { Instituto Municipal para las Mujeres y la } \\
\text { Equidad de Género de Tlalnepantla de Baz }\end{array}$ & $\begin{array}{l}\text { - No hay redes sociales para difundir acciones e } \\
\text { información. } \\
\text { En la página del ayuntamiento no se publica } \\
\text { información relevante sobre la violencia de } \\
\text { género. }\end{array}$ & Nulo \\
\hline Consejo Municipal de la Mujer de Chalco & $\begin{array}{l}\text { - El portal de Facebook no tiene publicaciones. } \\
\text { La página web del ayuntamiento muestra un } \\
\text { listado de actividades del Consejo en el que se } \\
\text { incluye la mitigación de la AVG. } \\
\text { - No se difunden información ni actividades. }\end{array}$ & Medio \\
\hline $\begin{array}{l}\text { Secretaría de las Mujeres Naucalpenses y } \\
\text { la Igualdad Sustantiva }\end{array}$ & No hay difusión de actividades. & Nulo \\
\hline $\begin{array}{l}\text { Instituto Municipal de la Mujer de Tultitlán. } \\
\text { Facebook: Instituto Municipal de la Mujer } \\
\text { de Tultitlán }\end{array}$ & $\begin{array}{l}\text { - Atención y asesoría jurídica y psicológica vía } \\
\text { portales web y teléfono. } \\
\text { Publicación constante en página web del } \\
\text { ayuntamiento y portal de Facebook de } \\
\text { infografías con información relevante sobre la } \\
\text { violencia en el contexto del confinamiento. }\end{array}$ & Alto \\
\hline $\begin{array}{l}\text { Instituto para la Protección de los } \\
\text { derechos de las mujeres Ixtapaluca. } \\
\text { Facebook: IPDMIxtapaluca }\end{array}$ & $\begin{array}{l}\text { - Publicaciones constantes y puntuales con } \\
\text { información relevante para denunciar e } \\
\text { identificar formas de violencia de género. } \\
\text { En la página web del ayuntamiento y en el } \\
\text { portal de Facebook se difunden acciones, } \\
\text { noticias, números de emergencia, infografías, } \\
\text { etcétera. }\end{array}$ & Alto \\
\hline $\begin{array}{l}\text { Dirección de atención a la mujer Valle de } \\
\text { Chalco Solidaridad. } \\
\text { Facebook: mujervalledechalcomx }\end{array}$ & $\begin{array}{l}\text { Publicación pausada (aproximadamente una publicación } \\
\text { al mes) sobre acciones realizadas por la dirección; } \\
\text { algunas de ellas relacionadas con violencia de género. }\end{array}$ & Medio \\
\hline $\begin{array}{l}\text { Instituto Municipal para la Igualdad entre } \\
\text { Mujeres y Hombres de Cuautitlán Izcalli }\end{array}$ & $\begin{array}{l}\text { - El portal web desglosa un listado de los } \\
\text { servicios que brinda el Instituto, así como } \\
\text { números telefónicos y una dirección; sin } \\
\text { embargo, no hay difusión de acciones, } \\
\text { actividades ni atención a la violencia de género } \\
\text { durante el confinamiento. } \\
\text { Los vínculos de la página de Facebook y de un } \\
\text { tríptico con más información sobre las acciones } \\
\text { están caídos. }\end{array}$ & Medio \\
\hline
\end{tabular}




\begin{tabular}{l|l}
\hline Instituto Municipal de la Mujer de Toluca. & $\begin{array}{l}\text { La difusión de información, acciones, sitios de interés, } \\
\text { números telefónicos de emergencia, atención y asesoría } \\
\text { es muy alta en el sitio web del ayuntamiento y en los } \\
\text { portales de Facebook y Twitter. }\end{array}$ \\
\begin{tabular}{l} 
Twitter: @mujer_toluca \\
\hline
\end{tabular}
\end{tabular}

Fuente: elaboración propia con base en datos de las páginas web de ayuntamientos y redes sociales de los organismos municipales de la mujer de febrero de 2020 a junio de 2021.

\section{Cuadro 8 \\ Campañas de la Secretaría de la Mujer del Estado de México para mitigar y atender la violencia de género durante el confinamiento por Covid}

\begin{tabular}{|c|c|}
\hline $\begin{array}{l}\text { Contingencia sin violencia } \\
\text { iEstamos contigo! } \\
\quad \text { \#NoEstásSola } \\
\quad \text { iDenuncia! } \\
\text { iNosotros te asesoramos y } \\
\text { acompañamos! } \\
\text { iNosotros te escuchamos! }\end{array}$ & $\begin{array}{l}\text { - Línea telefónica iDe hombre a hombre!-contención psicológica para varones en } \\
\text { - } \quad \text { Denunción de crisis. } \\
\text { electrónico y y número telefónico. } \\
\text { - Unidades de atención inmediata: convenio entre la Secretaría y el Grupo FIBRA } \\
\text { Macquarie para establecer en centros comerciales y establecimientos sitios en } \\
\text { los que se puedan realizar denuncias, solicitar asesoría psicológica y legal, en } \\
\text { caso de vivir una situación de violencia. } \\
\text { - Línea telefónica: Línea sin violencia. } \\
\text { - App de consulta y para generar denuncias: AppNaranja. } \\
\text { Unidades de Atención para Mujeres, sus Hijas e Hijos en situación de violencia: } \\
\text { durante la contingencia se implementaron } 10 \text { unidades regionales. }\end{array}$ \\
\hline $\begin{array}{c}\text { Campaña: } \\
\text { \#EnCasaMeSientoMejor } \\
\text { Que la violencia se quede } \\
\text { fuera de casa }\end{array}$ & $\begin{array}{l}\text { Guía para mujeres en situación de violencia que se encuentran en resguardo domiciliario } \\
\text { debido a la declaración de emergencia por Covid-19 en México. En esta guía se presenta } \\
\text { información útil para mujeres en riesgo de situaciones de violencia agravadas por el } \\
\text { confinamiento. Se enfatiza la erradicación de prejuicios que afectan la posibilidad de } \\
\text { nombrar ciertas conductas como violentas y se instruye y alienta a las mujeres a identificar } \\
\text { aquello que las daña, a la vez que se aportan herramientas como la Línea sin Violencia y la } \\
\text { App Naranja para evitar y denunciar situaciones de riesgo. }\end{array}$ \\
\hline
\end{tabular}

Fuente: elaboración propia con base en datos de la Secretaría de la Mujer del Estado de México (2020), actividades comprendidas entre febrero de 2020 y junio de 2021.

Nota: Referencias complementarias están sustentadas en la conferencia virtual de los programas y acciones de la Secretaría de la Mujer el 12 de mayo de 2021.

Debe notarse que las acciones registradas revistieron algunos rasgos de ajuste e innovación como la inclusión de apps de seguridad, infografías sobre los derechos de las mujeres, ligas para la atención telefónica, chats, botones de pánico y los nuevos portales de acceso a los servicios.

En el panorama de apoyos durante la pandemia es indispensable ubicar como parte de la agenda emergente los apoyos instrumentados por las dependencias del gobierno estatal dirigidos a toda la población femenina establecidos en espacios municipales, como la apertura en marzo de 2021 de 49 Centros Naranja de atención a mujeres en situación de violencia, 5 de ellos en Toluca, 2 en Ecatepec y en abril de 2021, la puesta en operación de una app para teléfono móvil denominada \#AppNaranja, para que las niñas, adolescentes y mujeres puedan obtener una atención más rápida y efectiva a la violencia (Ríos, 2021).

La estrategia es coordinada por la Secretaría de la Mujer y la Comisión de Derechos Humanos del Estado de México, apoyos que si bien no forman parte de la agenda municipal sí constituyen parte de una red de protección general y son el eje esencial, articulador de la política pública mexiquense (ver cuadro 8).

Asimismo, la exploración de la agenda municipal emergente observó, entre los efectos de la pandemia, que las dependencias a las que se encomiendan las políticas de género se vieron obligadas a cerrar sus puertas e incluso a la suspensión de sus pro- 
gramas y prestaciones, lo que hizo más difícil acceder a ellos. ${ }^{13}$ También se perfila la naturaleza de su actuar, dejando ver que con la etiqueta género se cubre un amplio espectro de actividades diversas y dispersas, no necesariamente relacionadas con los objetivos de lograr equidad y vigencia de derechos para las mujeres. La derivación hacia otros objetivos está relacionada con el hecho de que los gobiernos municipales encomiendan a los organismos de la mujer su participación en actividades relacionadas con programas cívicos y sociales, que son presentados con la denominación de género, por la intervención de mujeres en su realización. La discusión actual sobre la acción de las dependencias se ha traducido en algunos casos en iniciativas y propuestas sobre su eliminación.

En el caso de los municipios con declaratoria de Alerta de Violencia de Género, los desalentadores resultados muestran que esa agenda fue insuficiente y que esos procedimientos no tuvieron la eficiencia necesaria para brindar a las mujeres los apoyos necesarios para prevenir y erradicar la violencia.

La reflexión sobre esos puntos apunta a las dificultades de acceso para las usuarias que requieren apoyos, servicios o información; la evidencia confirma que los organismos municipales de las mujeres y los propios gobiernos municipales, como centros principales de comunicación, han prestado escasa atención a que sus espacios de contacto reflejen la oferta de los apoyos que pueden brindar en las situaciones de emergencia. La exploración de los campos de actividades de los organismos municipales de la mujer en educación, salud, trabajo y violencia muestra que no se han instrumentado estrategias para atender los impactos de la transformación de la vida en los hoga-

13 La medida fue parte de las prescripciones de la Secretaría de Salud que establecieron la suspensión de actividades no esenciales entre el 30 de marzo y el 30 de abril de 2020 (DOF, 2020b). Estas normas fueron sustituidas después por los semáforos epidemiológicos que mantuvieron, diferencialmente, las recomendaciones para el resguardo en el domicilio y la sana distancia. res por la Covid-19, los problemas de salud, la pobreza laboral, la pérdida del empleo, los ingresos y el salario. Se advierte que los apoyos sustantivos a esas situaciones son escasos o nulos, la atención es regional, no alcanza los espacios locales o de comunidad. Asimismo, no considera el teletrabajo, la atención a los hijos, las cargas del trabajo doméstico, no se ofrecen apoyos sustantivos de prevención al riesgo o que brinden mejoras en las condiciones de bienestar.

En el mismo sentido en el contenido de las publicaciones se observa un discurso ambiguo que destaca el interés de los gobiernos en su atención con frases como: iNo estás sola!; no obstante, en la práctica, el acceso resulta difícil para las usuarias potenciales de prestaciones como auxilio, vigilancia, albergue, apoyos a problemas de salud, educativos o distanciamiento de sus agresores.

\section{A modo de conclusión: la integración de la agenda, abriendo el camino entre las barreras}

El recorrido por la difusión emprendida por los gobiernos locales para enfrentar la pandemia ha dejado ver sus limitaciones en la configuración de una Agenda Municipal Emergente para apoyar a las mujeres, brindarles servicios y proporcionarles espacios de asesoría o protección. En el nivel heterogéneo de los municipios la exploración permitió vislumbrar los retos que enfrenta el establecimiento de una comunicación estratégica de los gobiernos con sus ciudadanos.

Las observaciones en medios de difusión muestran que las mujeres han enfrentado numerosos obstáculos en el camino para obtener apoyos, servicios o acompañamiento para los problemas que se vivieron durante la pandemia, muchos de los cuales siguen teniendo continuidad, aun cuando la fase de confinamiento ya ha sido superada en muchos lugares. Desde otros ángulos, la mirada sobre la agenda municipal aporta elementos para considerar que los gobiernos también enfrentan barreras para establecer la comunicación que les permita 
obtener respuestas colaborativas, de participación e intercambio con los ciudadanos. Desde esas vías se destaca que las redes sociales y los medios digitales se convierten en mediadores en los conflictos de interés público y son una herramienta valiosa en la prevención y atención a los problemas que afectan a los ciudadanos.

En esta visión deben tenerse en cuenta las dificultades para obtener la información sobre los mecanismos de difusión, lo que confiere un cierto carácter especulativo a los rasgos que les son atribuidos. Se estima, no obstante, que el perfil que se configura sobre la comunicación enfatiza el imperativo de avanzar, desde los espacios locales, en estrategias capaces de innovar y mejorar la atención a los problemas que afectan a las mujeres. Asimismo, en ese contexto es pertinente considerar que la exploración realizada deja abierta la interrogante sobre las capacidades generales de los gobiernos municipales para la integración de una Agenda Municipal Emergente de Género, respuesta que requiere de su ampliación a otras perspectivas analíticas.

La exploración de las actividades de difusión de los municipios durante la pandemia también dejó ver que aun cuando responden a la intención de atender e informar a los ciudadanos reflejan también la percepción extendida en la sociedad que ubica a las mujeres como víctimas o receptoras pasivas con limitadas capacidades de autogestión. En el mismo sentido, se puede afirmar que las políticas del gobierno federal no han marcado líneas definidas o metas claras en términos de objetivos de género y se han movido de manera contradictoria en la asignación de recursos a los programas que pueden realizar las instancias municipales.

Las tensiones y las diferencias de posición entre la Federación y otros niveles de gobierno fueron públicas y se enmarcaron desde la óptica negacionista del gobierno central a la gravedad de la crisis, hasta su mirada reduccionista de los problemas que afectan a las mujeres; posición que ha puesto en cuestionamiento la aplicación de una perspectiva de género en las políticas públicas, sobre todo porque los municipios dependen de recursos federales para operar los programas. Así como lo recomienda la Comisión Económica para América Latina y el Caribe, las estrategias que se adopten para enfrentar la crisis deben implementarse fortaleciendo el trabajo coordinado con los mecanismos para el adelanto de las mujeres, y contando con la participación de las organizaciones y los movimientos de mujeres y feministas, de mujeres indígenas, afrodescendientes, rurales y de las comunidades de base, a fin de que contribuyan al diseño de estas estrategias adaptándolas a sus realidades (ONU Mujeres-CEPAL, 2020). Finalmente es conveniente destacar que la difusión de las acciones públicas es crucial para avanzar en la convivencia en los espacios comunitarios; sería deseable entonces que los gobiernos municipales le dieran la importancia que reviste.

\section{Fuentes consultadas}

Alzate-Zuluaga, Mary Luz y Romo Morales, Gerardo (2017), "La agenda pública en sus teorías y aproximaciones metodológicas. Una clasificación alternativa", Revista Enfoques, 15 (26), Santiago de Chile, Universidad Central de Chile, pp. 13-35, <https://acortar.link/OG9fko>, 18 de noviembre de 2021.

Baca Tavira, Norma (2002), "Experiencias y significados del contexto del hogar en la relación trabajo doméstico-extradoméstico", Papeles de población, 8 (32), Toluca, Universidad Autónoma del Estado de México, pp. 199-243, <https:// acortar.link/XQaLOc>, 18 de noviembre 2021.

Berger, Peter y Luckmann, Thomas (1997), Modernidad, pluralismo y crisis de sentido. La orientación del hombre moderno, Barcelona, Editorial Paidós.

Carrillo, Ana María (2021), "De la fiebre amarilla a la Covid-19: Dos siglos de epidemias y pandemias en México", Korpus 21, 1 (2), Zinacantepec, El Colegio Mexi- 
quense, A.C., pp. 233-250, doi: https:// doi.org/10.22136/korpus21202132

CEPAL (Comisión Económica para América Latina y el Caribe) (2021), "Informe especial Covid-19. La autonomía económica de las mujeres en la recuperación sostenible y con igualdad", núm. 9, 10 de febrero, Santiago de Chile, CEPAL, <https://acortar.link/rXOI5e>, 25 de septiembre de 2021.

CONAVIM (Comisión Nacional para Prevenir y Erradicar la Violencia Contra las Mujeres) (2020), "Oficio núm. 222B021aO/539/2020", Metepec, Gobierno del Estado de México, <https:// acortar.link/zy3s70>, 19 de mayo de 2021.

Coneval (Consejo Nacional de Evaluación de la Política de Desarrollo Social) (2021), La política social en el contexto de pandemia por el virus SARS-COV-2 (COVID19) en México, Ciudad de México, Consejo Nacional de Evaluación de la Política Social, Coneval, <https://acortar.link/R27kOs>, 25 de septiembre de 2021.

Dearing, James W. y Rogers, Everett $M$. (1996), Comunication concepts 6: Agenda Setting, California, Thousand Oaks, Sage Publications.

DOF (Diario Oficial de la Federación) (2020a), "Acuerdo por el que se establecen acciones extraordinarias para atender la emergencia sanitaria generada por el virus sars-cov2", 31 de marzo, Ciudad de México, Secretaría de Salud, <https://acortar.link/gmac8Q>, 25 de septiembre de 2021.

DOF (Diario Oficial de la Federación) (2020b), "Acuerdo por el que se declara como emergencia sanitaria por causa de fuerza mayor, a la epidemia de enfermedad generada por el virus Sars-Cov2 (covid-19)", 30 de marzo, Ciudad de México, Consejo de Salubridad General, <https://acortar.link/eSLDPA>, 25 de septiembre de 2021.
Gaceta del Gobierno (2015), "Decreto del Ejecutivo del Estado para atender la declaratoria de Alerta de Violencia de Género contra las Mujeres para el Estado de México", 3 de noviembre, Toluca, Poder Ejecutivo del Estado de México, <https://acortar.link/zOBA9r>, 25 de septiembre de 2021.

García Guzmán, Brígida (2019), "El trabajo doméstico y de cuidado: su importancia y principales hallazgos en el caso mexicano", Estudios demográficos y urbanos, 34 (2), Ciudad de México, El Colegio de México, pp. 237-267, doi: https://doi.org/10.24201/edu.v34i2.1811

Graham, Melissa; Avery, Elizabeth y Park, Sejin (2015), "The role of social media in local government crisis communications", Public Relations Review, 41, Ámsterdam, Elsevier, pp. 386394, doi: https://doi.org/10.1016/j.pubrev.2015.02.001

Guadarrama, Gloria (2021), "Agenda mexiquense municipal de género. Ajustes y limitaciones en tiempos de COVID-19", Revista Cofactor, 10 (19), Toluca, Gobierno del Estado de México-Consejo de Investigación y Evaluación de la Política Social (CIEPS) del Estado de México, pp.10-31, <https://acortar. link/O8OaZW>, 8 de octubre de 2021.

Hevia, Constantino y Neumeyer, Andy (2020), Un marco conceptual para analizar el impacto económico del COVID-19 y sus repercusiones en las políticas, Nueva York, PNUD América Latina y El Caribe, <https://acortar.link/ jYq83>, 20 de noviembre de 2021.

Inegi (Instituto Nacional de Estadística y Geografía) (2020), "Resultados de la Encuesta Nacional de Ocupación y Empleo (ENOE)", cifras oportunas de julio 2020, Ciudad de México, Inegi, <https://acortar.link/bvORw1>, 19 de mayo de 2021.

Inmujeres (Instituto Nacional de las Mujeres) (2020), "Covid-19 y su impacto en números desde la perspectiva de género", Ciudad de México, Inmujeres, <https:// 
acortar.link/WMBdkx>, 25 de septiembre de 2021.

Kitroeff, Natalie (2020), "En México el presidente dice que la mayoría de las llamadas de violencia doméstica son falsas", The New York Times, 31 de mayo, Ciudad de México, The New York Times Company, América Latina, <https:// acortar.link/YY8LS2>, 19 de mayo de 2021.

Malaver-Fonseca, Luisa Fernanda; Serrano-Cárdenas, Lizeth y Castro-Silva, Hugo Fernando (2021), "La pandemia COVID-19 y el rol de las mujeres en la economía del cuidado en América Latina: una revisión sistemática de literatura", Estudios Gerenciales. Journal of Management and Economics for Iberoamerica, 37 (158), Santiago de Cali, Universidad ICESI, pp. 153-163, doi: https://doi. org/10.18046/j.estger.2021.158.4458

Montes de Oca Zavala, Verónica; Alonso Reyes, María del Pilar; Montero López, Lena María y Vivaldo-Martínez Marissa (2021), "Sociodemografía de la desigualdad por Covid-19 en México", Revista Mexicana de Sociología, 83 (número especial), Ciudad de México, UNAM, pp. 67-91, <https://acortar.link/ AQUyaf>, 7 de octubre de 2021.

Olivera Lozano, Fidel y Olivera Lozano, Guillermo (2021), "Efecto crítico de la pandemia por Covid-19 en el empleo en México", Carta Económica Regional, 34 (128), Guadalajara, Universidad de Guadalajara, pp. 27-58.

ONU Mujeres-CEPAL (Organización de las Naciones Unidas para la Igualdad de Género y el Empoderamiento de la Mujer-Comisión Económica para América Latina y el Caribe) (2020), "Cuidados en América Latina y el Caribe en tiempos del Covid-19. Hacia sistemas integrales para fortalecer la respuesta y la recuperación", Santiago de Chile, CEPAL, <https://acortar.link/wuRXYn>, 25 de septiembre de 2021.

Pautassi, Laura Cecilia (2021), "A un año de la pandemia: Los cuidados en el centro y en los márgenes", Desenvolvimento em Debate, 9 (1), Río de Janeiro, Instituto Nacional de Ciência e Tecnología em Políticas Públicas, Estratégias e Desenvolvimento, pp. 213 229, doi: http://dx. doi.org/10.51861/ded.dmvu.1.019

Pautassi, Laura Cecilia (2020), "La centralidad del derecho al cuidado en la crisis de COVID-19 en América Latina. Oportunidades en riesgo", IUS ET VERITAS, núm. 61, Lima, Universidad Católica del Perú, pp. 78-93, doi: https://doi. org/10.18800/iusetveritas.202002.005

Poder Legislativo del Estado de México (2021) (última actualización, 17 de marzo de 2021), "Alistan en el Congreso 260 mdp para combatir feminicidios y desapariciones. Comunicado de Prensa, núm. 2751", Toluca, Cámara de Diputados LX Legislatura, <https://acortar.link/bxbtgZ>, 19 de mayo de 2021.

Power, Kate (2020), "The Covid-19 pandemic has increased the care burden of women and families", Sustainability: Science, Practice and Policy, 16 (1), Londres, Taylor and Francis Group, pp 6773, doi: https://doi.org/10.1080/154877 33.2020.1776561.

Rea Ángeles, Patricia; Montes de Oca Zavala, Verónica y Pérez Guadarrama, Karla (2021), "Políticas de cuidado con perspectiva de género", Revista Mexicana de Sociología, 83 (3), Ciudad de México, UNAM, pp. 547580, doi: http://dx.doi.org/10.22201/ iis.01882503p.2021.3.60132

Ríos, Elizabeth (2021), "Abren 49 Centros Naranja en Edomex", El Sol de Toluca, 8 de marzo, Toluca, Organización Editorial Mexicana, Portada, <https://acortar.link/Ry54MU>, 10 de marzo de 2021.

Ríos Cázares, Alejandra (2014), "Los institutos estatales de la mujer: diagnóstico, retos y perspectivas", en Marcia de Castro y María del Carmen Sacasa Ventura (coords.), Indicadores de desarroIlo humano y género en México: nueva metodología. Identificar las barreras para lograr la igualdad, Ciudad de Mé- 
xico, PNUD, pp. 23-50, <https://acortar.link/pXnFCj>, 19 de mayo de 2021.

Ruiz Coronel, Alí (2021), "Covid-19 en una familia en situación de calle", Revista Mexicana de Sociología, (Número Especial), México, UNAM, pp. 193220, doi: http://dx.doi.org/10.22201/ iis.01882503p.2021.0.60173

Secretaría de la Mujer del Estado de México (2020), "Guía para mujeres en situación de violencia que se encuentran en resguardo domiciliario debido a la declaración de emergencia por COVID-19 en México", Toluca, Gobierno del Estado de México, <https://acortar.link/ cQYzni>, 27 de septiembre de 2021.

SESNSP (Secretariado Ejecutivo del Sistema Nacional de Seguridad Pública) (2021), "Información sobre violencia contra las mujeres. Incidencia delictiva y llamadas de emergencia 9-1-1 Información con corte al 31 de julio de 2021", Ciudad de México, Centro Nacional de Información, <https://acortar.link/t29uvC>, 25 de septiembre de 2021.

SESNSP (Secretariado Ejecutivo del Sistema Nacional de Seguridad Pública) (2020). "Información sobre violencia contra las mujeres. Incidencia delictiva y llamadas de emergencia 911: con corte el 30 de abril de 2020", Ciudad de México, Centro Nacional de Información,<https://www.gob.mx/sesnsp>, 18 de mayo de 2021.

SESNSP (Secretariado Ejecutivo del Sistema Nacional de Seguridad Pública) (2019), "Información sobre violencia contra las mujeres. Incidencia delictiva y Ilamadas de emergencia 9-1-1 Información con corte al 31 de diciembre de 2020", Ciudad de México, Centro Nacional de Información, <https://acortar.link/ Oc3EdO>, 25 de septiembre de 2021.

SESNSP (Secretariado Ejecutivo del Sistema Nacional de Seguridad Pública) (2015 a 2021)," Datos de víctimas del fuero común", Ciudad de México, Centro Nacional de Información, <https://acortar. link/VuVsKj>, 25 de septiembre de 2021.
Torres Santana, Ailynn (2020), "La carga de los cuidados", Nexos, 1 de noviembre, (515), Ciudad de México, Nexos, pp. 44-46. <https://nexos.com. $m \times / ? p=50904>$, 19 de mayo de 2021.

Ziccardi, Alicia (2020), "Condiciones de habitabilidad de las viviendas y del entorno urbano ante el aislamiento social impuesto por Covid 19 (Informe preliminar)", Ciudad de México, UNAM, <https://acortar.link/jb8Ncr>, 25 de septiembre de 2021.

Recibido: 28 de septiembre de 2021. Aceptado: 15 de noviembre de 2021. Publicado: 6 de enero de 2022.

\section{Gloria Jovita Guadarrama Sánchez}

Es doctora en Ciencias Políticas y Sociales por la Universidad Nacional Autónoma de México y miembro del Sistema Nacional de Investigadores, nivel II. Actualmente se desempeña como docente investigadora en El Colegio Mexiquense, A.C. Sus líneas de investigación son: instituciones, políticas públicas, género, asistencia social, sociedad civil y tercer sector. Entre sus más recientes publicaciones se encuentran, como autora: "El modelo de fundaciones comunitarias en México", Cooperativismo \& Desarrollo, 27 (115), Bogotá, Universidad Cooperativa de Colombia, pp. 1-27 (2019); como coautora: "La apropiación y el uso del espacio público urbano. Los comunes en el parque urbano", Economía, Sociedad y Territorio, 21 (65), Zinacantepec, El Colegio Mexiquense, A.C., pp. 57-85 (2021); "Gobernanza y derecho al agua: Prácticas comunes y particularidades de los comités comunitarios de agua potable", Sociedad y Ambiente, 20 (2019), San Cristóbal de Las Casas, El Colegio de la Frontera Sur, pp. 53-77 (2019); como co-coordinadora: ¿Problemas complejos, soluciones nuevas? Debates sobre el desarrollo social sustentable en el Estado de México, Zinacantepec, El Colegio Mexiquense, A.C. (2019). 